\title{
Selection of Best Fit Correlation for Compression Index of Soil from District Bannu
}

\author{
ZIA UR RAHMAN*, SIRAJUDDIN*, AIZAZ AHMAD KHAN*, AND MATIULLAH* \\ RECEIVED ON 25.09.2017 ACCEPTED ON 25.05.2018 \\ ABSTRACT
}

\begin{abstract}
Geotechnical investigation is one of the major steps in the safe and economic design of foundation for any structure. This requires some soil parameters to be established. CI (Compression Index) is one of these parameters. The stability of a foundation is not fully justified as long as the magnitude of settlement is unknown. The problem arises when the value of $\mathrm{CI}$ is needed badly and a consolidation test is set up for this purpose which consumes almost 3 days for its completion provided that the assembly would not be disturbed. Little amount of disturbance can cause serious error in further calculations and plotting of data. Undisturbed soil sample is the primary demand of consolidation test which is a tough job for a person having not been experienced very much in the fieldwork. In order to overcome these complexities, the researchers have established various correlations between compression index and some basic soil properties like Atterberg limits, void ratio, natural moisture content and OMC (Open Moisture Content), as they are simple to be determined and takes small amount of time. This research has been conducted on soil samples collected from a single spot at an interval of $5 \mathrm{ft}$ depth for the sake of validation of a suitable correlation for Bannu District, KPK (Khyber Pakhtunkhwa), Pakistan so that the determination of compression index becomes simple and convenient.
\end{abstract}

Key Words: Consolidation, Undisturbed, Compression Index, Correlation, Parameters.

\section{INTRODUCTION}

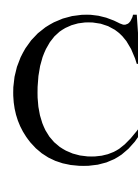

oefficient of volume compressibility is useful when calculating settlement under loads but its variation with confining pressure reduces its importance. Therefore, the $\mathrm{CI}$ is more preferred as it does not change with the confining pressure [1]. As the biggest problem is the determination of this parameter in the laboratory hence numerous researchers made an attempt to correlate this with the index properties of soil which are easy to determine. Different researchers targeted different types of soil such as remolded, undisturbed, high plasticity and low plasticity clays tabulated as shown in Table 1 [2].

Terzaghi and Pecks [15] correlation is the most popular in this regard and used extensively in geotechnical problems but there are certain facts that must be considered while doing so.

Authors E-Mail: (zrahman03@gmail.com, Sirajuddin863@gmail.com, imaizazst96@gmail.com, matiullah00999@gmail.com)

* Department of Civil Engineering, University of Engineering \& Technology, Campus-III, Bannu, Peshawar, Pakistan.

This is an open access article published by Mehran University Research Journal of Engineering and Technology, Jamshoro under the CC by 4.0 International License. 
(1) Weather the type of soil is the same as was experimented upon by Terzaghi and Peck [15].

(2)

The conditions of the sample recovery are consistent or not.

If the answer is yes then this correlation is OK but if the answer is no, then it might not yield appropriate results. This may be witnessed from the work of other researchers such as Skempton [3] who worked on disturbed and remolded clay samples and arrived at the following correlation.

$\mathrm{C}_{\mathrm{c}}=0.007(\mathrm{LL}-7)$

Koppula and Wrothetal [4] proposed a correlation using the PI (Plasticity Index) for primary compressive strength of remolding clay.

$\mathrm{C}_{\mathrm{c}}=0.1325\left(\mathrm{I}_{\mathrm{p}}\right)$

An attempt was made to develop a model between PI and CI by carrying out linear regression analysis on the results of 44 samples. The results were found satisfactory as the value of coefficient of determination $\left(\mathrm{R}^{2}\right)$ was 0.898 [5].

Singh and Noor [6] were the two Indian researchers who conducted similar study to the one executed over here. They made use of the linear regression analysis to evaluate the best fit correlation for CI by comparing it to various index properties of soil that were easy to be determined. The deviation of predicted values from the actual values were found out by the determination of RMSE (Root Mean Squared Error). They extracted the conclusive model which was found to be the best fit with less error as follows [6].

$\mathrm{C}_{\mathrm{c}}=0.002 \mathrm{a}+0.0025 \mathrm{~b}-0.005$

Where a is LL (Liquid Limit), b is PI (Plasticity Index)
When plotted it gives smaller value of RMSE which is 0.036 hence this plot shows maximum level of accuracy as compared to the other two. This article provides the basis of the research work under consideration except the area of study and methodology of sample collection.

Another research study of the same nature was conducted by correlating several basic properties of soil such as maximum dry density, optimum moisture content with CI. About 22 samples were tested in the lab and the results compared which were in close resemblance [7]. This study was carried out by many other researchers with the difference of region and soil type [8-12].

The questions that arise are that how much reliable these results are? And why a particular model has been selected for this purpose? This is based upon subjectivity most of the times. Bayesian probabilistic approach was introduced for this purpose to carry out multivariate regression for CI. The initial void ratio and liquid limit possess highest degree of plausibility among various classes of formulas [13]. A more sophisticated approach is utilized in [14] in order to improve the accuracy, reliability and predicting power of the correlations. Which makes use of the AI (Artificial Intelligence) for resolving a particular problem or issue.

\section{MATERIALS AND METHOD}

The CI of undisturbed soil sample was determined using the conventional 1D-consolidation test carried out according to ASTM, D-2435. The sample was collected with the help of Shelby tube also known as thin walled sampler shown in (Fig. 1).

The technique of auger boring was utilized to probe into the ground up to a depth of $25 \mathrm{ft}$ with a diameter of 5 inches. The sample was recovered at each $5 \mathrm{ft}$ interval so 
that the variation of CI with the depth could be investigated. This is depicted in (Fig. 2). As the sample at one depth was obtained, the borehole was advanced further. In the lab the sample was tested in two ways. The consolidation test was conducted in order to get the realtime value of $\mathrm{C}_{\mathrm{c}}$. While the index properties of soil like liquid limit, plastic limit, water content, specific gravity and $\mathrm{OMC}$ were determined and incorporated into the correlations to find the parallel set of values of $\mathrm{C}_{\mathrm{c}}$. Three most suitable correlations were selected based upon the conditions of Bannu soil for this purpose that of Terzaghi and Peck [15], Nishida [16], Singh and Noor [6]. Both the calculated and actual values were compared using Microsoft excel application for all the three mentioned correlations.

\section{RESULTS AND DISCUSSION}

As the testing session was complete, the results were compiled in the form of tables and graphs that helped understand the trends and findings. First of all, Terzaghi and Peck's [15] correlation was checked against the actual value of CI obtained from consolidation test as indicated in Table 1. Tables 2-4 comprises of the results for Nashida [16] Singh and Noor [6] correlations respectively. These tables do not give the perfect picture of the comparative values. This is why all the three correlations have been combined together with the actual values on a plot which effectively demonstrates the concluding remarks as given in Fig. 3.

$\mathrm{C}_{\mathrm{c}}=0.009(\mathrm{LL}-10)$ for undisturbed clays

$\mathrm{C}_{\mathrm{c}}=1.15\left(\mathrm{e}_{\mathrm{o}}-0.27\right)$ for all clays

$\mathrm{C}_{\mathrm{c}}=0.002 \mathrm{LL}+0.0025 \mathrm{PI}-0.005$ for fine grained soils

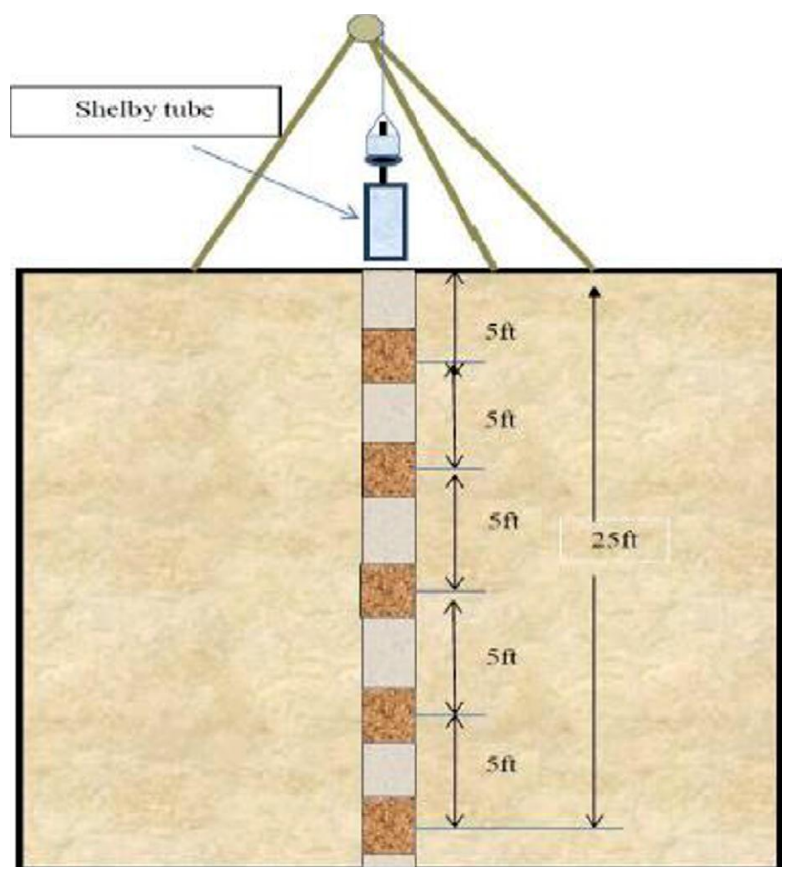

FIG. 2. SCHEMATIC DIAGRAM OF SAMPLING PLAN

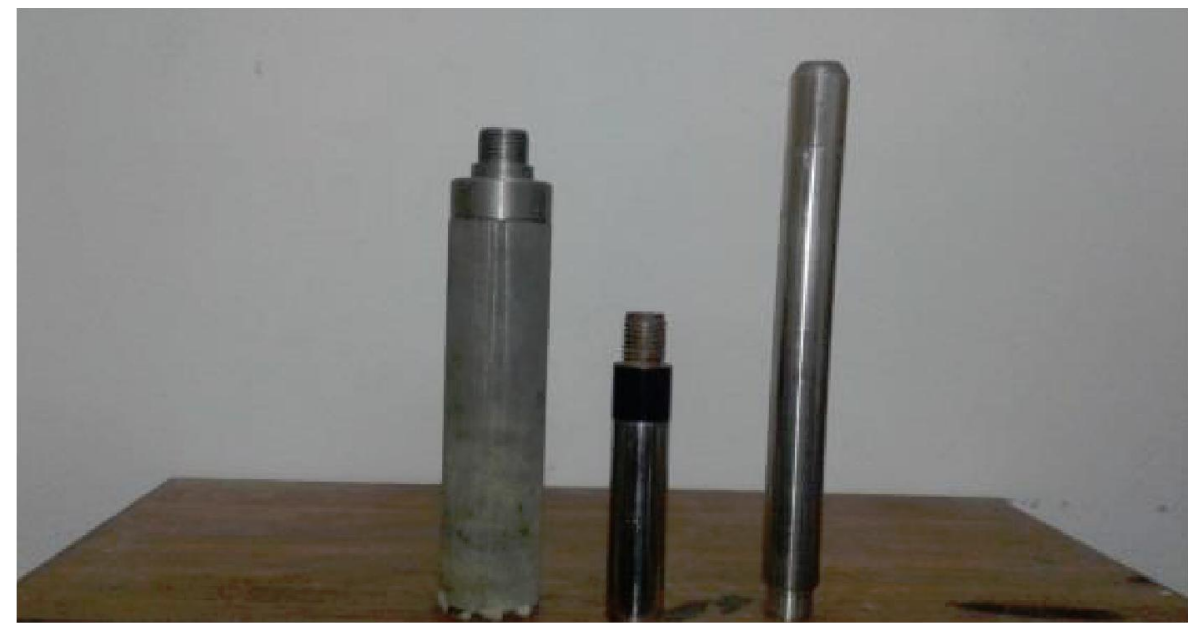

FIG. 1. PICTURE OF SHELBY TUBE ALONG WITH CONNECTORS

Mehran University Research Journal of Engineering \& Technology, Volume 38, No. 1, January, 2019 [p-ISSN: 0254-7821, e-ISSN: 2413-7219] 
TABLE 1. FEW CORRELATIONS WORKED OUT EARLIER

\begin{tabular}{|c|c|c|c|}
\hline No. & Correlation for $\mathrm{cc}$ & Type of Soil/Comments & Reference \\
\hline 1. & 0.009 (LL - 10) & Moderately saturated clay & Terzaghi and Peck [15] \\
\hline 2. & $0.1325 \mathrm{Ip}$ & Remolded clay & Kappula [4] \\
\hline 3. & $0.141 \mathrm{Gs}$ (ysat/ydry)2.4 & All clayey samples & Renden-Herero [17] \\
\hline 4. & $0.0093 \mathrm{wc}$ & Canada clays & Kappula [4] \\
\hline 5. & $1.15(\mathrm{eo}-0.35)$ & All clays & Nishida [16] \\
\hline 6. & $0.00234 \mathrm{LL} * \mathrm{Gs}$ & All inorganic clays & Nagaraj and Srinavasa [18] \\
\hline 7. & $0.046+0.0104 \mathrm{PI}$ & When $\mathrm{PI}<50 \%$ & Nakase et. al. [19] \\
\hline
\end{tabular}

TABLE 2. COMPARISON OF VALUES OF COMPRESSION INDEX FOR TERZAGHI AND PECK CORRELATION [15]

\begin{tabular}{|c|c|c|c|c|}
\hline \multirow{2}{*}{ Sample No. } & \multirow{2}{*}{ Depth (ft.) } & Liquid Limit & \multicolumn{2}{|c|}{ Compression Index $\left(\mathrm{C}_{\mathrm{C}}\right)$} \\
\cline { 3 - 5 } & & & Terzaghi and Peck & Actual Value \\
\hline 1 & 5 & 34.3 & 0.219 & 0.105 \\
\hline 2 & 10 & 38.93 & 0.260 & 0.104 \\
\hline 3 & 15 & 35.34 & 0.228 & 0.101 \\
\hline 4 & 20 & 34.34 & 0.219 & 0.062 \\
\hline 5 & 25 & 39.36 & 0.264 & 0.043 \\
\hline
\end{tabular}

TABLE 3. COMPARISON OF VALUES OF COMPRESSION INDEX FOR NASHIDA [16]

\begin{tabular}{|c|c|c|c|c|}
\hline \multirow{2}{*}{ Sample No. } & \multirow{2}{*}{ Depth (ft.) } & Liquid Limit & \multicolumn{2}{|c|}{ Compression Index $\left(\mathrm{C}_{\mathrm{C}}\right)$} \\
\cline { 4 - 5 } & & & Terzaghi and Peck & Actual Value \\
\hline 1 & 5 & 0.9510 & 0.724 & 0.105 \\
\hline 2 & 10 & 0.910 & 0.736 & 0.104 \\
\hline 3 & 15 & 0.465 & 0.224 & 0.101 \\
\hline 4 & 20 & 0.841 & 0.657 & 0.062 \\
\hline 5 & 25 & 0.969 & 0.804 & 0.043 \\
\hline
\end{tabular}

TABLE 4. COMPARATIVE VALUES OF COMPRESSION INDEX FOR SHAHID AND AMERDEEP [6]

\begin{tabular}{|c|c|c|c|c|c|}
\hline \multirow{2}{*}{ Sample No. } & \multirow{2}{*}{$\begin{array}{c}\text { Depth } \\
\text { (ft.) }\end{array}$} & Liquid Limit & PI = LL - PL & \multicolumn{2}{|c|}{ Compression Index $\left(\mathrm{C}_{\mathrm{C}}\right)$} \\
\cline { 4 - 6 } & 5 & & & Correlation & Actual Value \\
\hline 1 & 10 & 34.30 & 11.89 & 0.093 & 0.105 \\
\hline 2 & 15 & 35.34 & 16.38 & 0.114 & 0.104 \\
\hline 3 & 20 & 34.34 & 10.75 & 0.093 & 0.101 \\
\hline 4 & 25 & 39.36 & 12.69 & 0.092 & 0.062 \\
\hline 5 & & & 0.105 & 0.043 \\
\hline
\end{tabular}


The bar charts shown in Figs. 3-5 in combination with its relevant tabulated data, clearly depicts the comparison amongst the values of CI obtained both from correlations and lab tests. The values of SD (Standard Deviation) mean and coefficient of variation have been calculated and shown on the relevant charts. If carefully analyzed the value of SD, Singh and Noor [6] is the one correlation which bears minimum value.
Hence the results of this correlation are less scattered and shows small deviation from the mean value. The mean value for CI concluded from lab test is 0.083 while Singh and Noor [6] gives a mean value of 0.099. This value also encourages the idea of suitability of the particular correlation because of the big comparative difference with the other two values which are 0.238 and 0.629 .

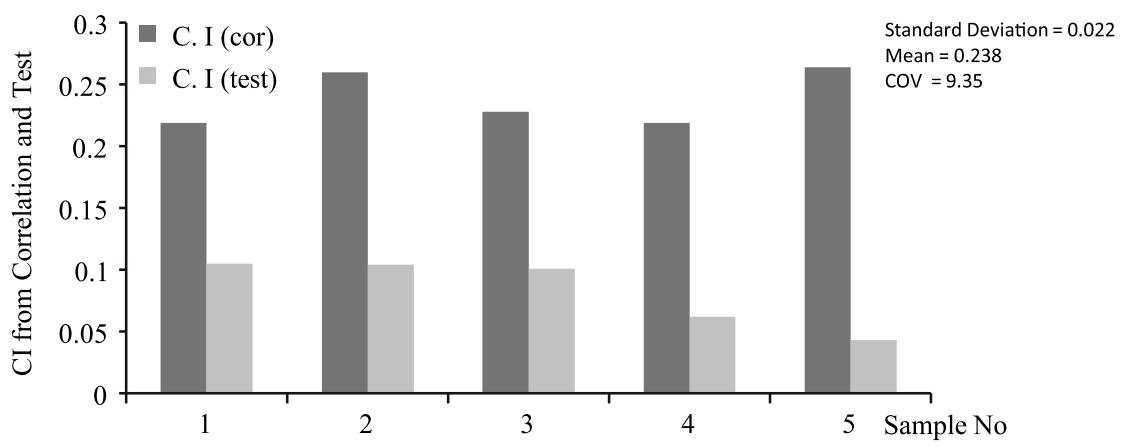

FIG. 3. COMPARISON OF COMPRESSION INDEX VALUES [15]

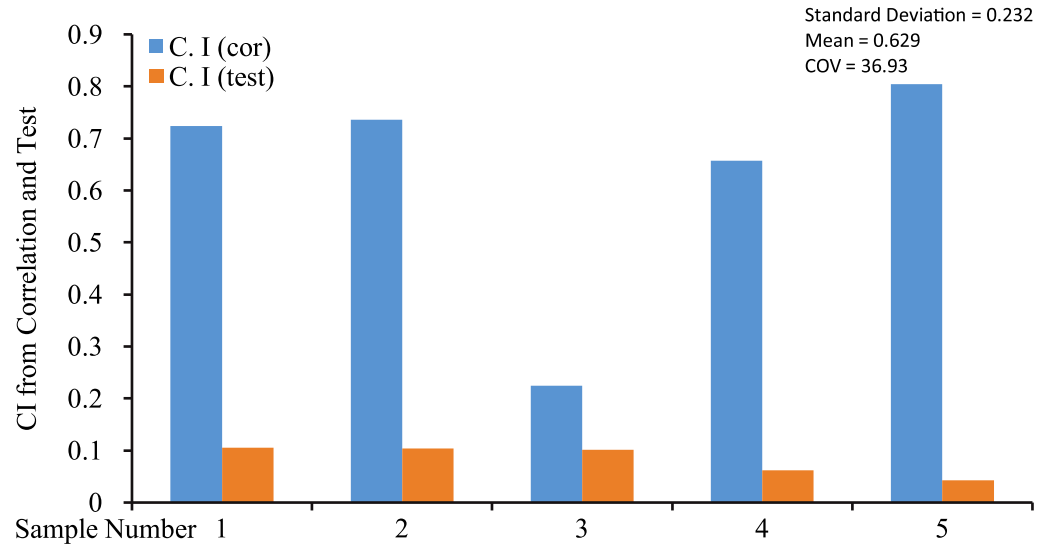

FIG. 4. COMPARISON OF COMPRESSION INDEX VALUES [16]

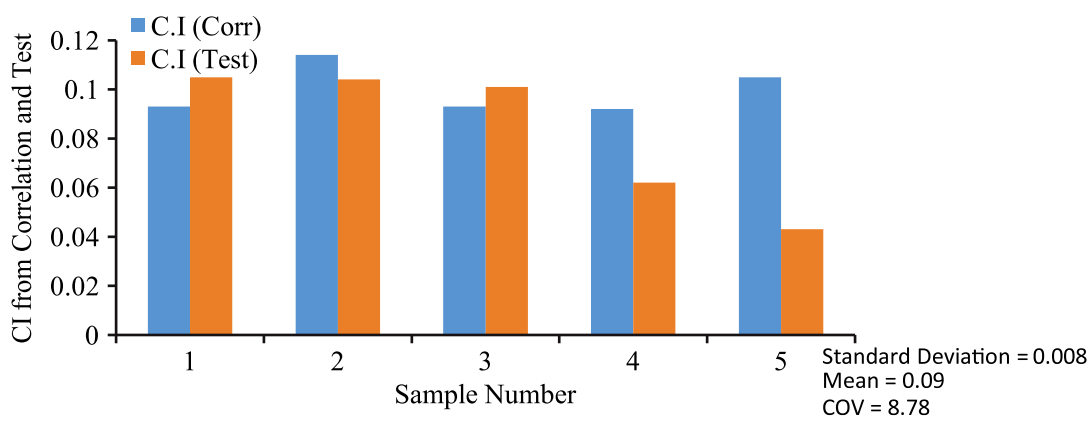

FIG. 5. COMPARISON OF COMPRESSION INDEX VALUES [6] 


\section{CONCLUSION}

The conclusion drawn after going through the entire procedure can be described as, "The results yielded by a correlation which was developed in 2012 are in very close resemblance with those came out from consolidation test. Hence the suitability of this correlation for finding $\mathrm{CI}$ is hereby confirmed and recommended for all geotechnical engineers and consultants working out on projects in District Bannu, KPK. This study was carried out to a depth of $30 \mathrm{ft}$ and with no water table.

\section{RECOMMENDATIONS}

It is strongly recommended that this study should be extended to a big area and more number of samples should be collected and tested in order to fulfill the demands of regression analysis. This research should be exercised in those regions where water table is high as this study does not cover this aspect.

\section{ACKNOWLEDGEMENT}

The cooperation and assistance offered by the Chairman, Department of Civil Engineering, and Technical staff of Soil Mechanics Lab., University of Engineering \& Technology, Peshawar, Campus-III, should be highly acknowledged. It was their support and favor, which helped to complete this research study.

\section{REFERENCES}

[1] Carter, M., and Bentley, P.S., "Soil Properties and their Correlations", John Wiley \& Sons, Ltd, (Online), $2^{\text {nd }}$ Edition, pp. 58-60, UK, August, 2016.

[2] Bowles, J.E., "Foundation Analysis and Design", McGrawHill, Peoria, Illinois, $5^{\text {th }}$ Edition, Chapter-2, pp. 89, 1997.

[3] Vinod, P., and Bindo, J., "Compression Index of Highly Plastic Clays- An Empirical Correlation", Indian Geotechnical Journal, Volume. 40, No. 3, pp. 174-180, 2010 .

[4] Koppula, S., "Statistical Estimation of Compression Index," Geotechnical Testing Journal, Volume 4, No. 2, pp. 68-73, 1981.

[5] Jain, K.V., Dixit, M., and Chitra, R., "Correlation of Plasticity Index and Compression Index", International Journal of Innovations in Engineering and Technology, Volume 5, No. 3, June, 2015.
Singh, A., and Noor, S., "Soil Compression Index Prediction Model for Fine Grained Soils", International Journal of Innovations in Engineering and Technology, Volume 1, No. 4, December, 2012.

[7] Kumar, R., and Jain, P.K., "Prediction of Compression Index of Fine Grained Remolded Soil from Basic Soil Properties", International Journal of Applied Engineering Research, Volume 11, No. 1, pp. 592-598, 2016.

[8] Sathyanarayana, B., Reddy, and Sathyanarayana, C.N.V.S., "Development of Empirical Equation for Compressibility of Marine Clays", Indian Geotechnical Conference, GEO Trends, IGS Mumbai Chapter \& IIT Bombay, December 16-18. 2010.

[9] Widodo, S., and Ibrahim, A., "Estimation of Primary Compression Index (CC) Using Physical Properties of Pontianak Soft Clay", International Journal of Engineering Research and Applications, Volume 2, No. 5, September- October, 2012.

[10] Onyejekve, S., and Kang, X., “Assessment of Empirical Equations for the Compression Index of Fine Grained Soil and Missouri", Bulletin of Engineering Geology and the Environment, the Official Journal of IAEG, [ISSN: 1435-9529], 7 August, 2014.

[11] Akayuli, C.F.A., and Ofosu, B., "Empirical Model for Estimating Compression Index from Physical Properties of Weathered Birinian Phyllities", Electronic Journal of Geotechnical Engineering, Volume 18, pp. 6135-6144, 2013.

[12] Mc-Cabe, B.A., and Brian, B., "Empirical Correlation for the Compression Index of Irish Soft Soils", Proceedings of ICE, Geotechnical Engineering, Volume 167, pp. 510-517, 2014.

[13] Yan, W.M., Yuen, K.V., and Yoon, G.L., "Bayesian Probabilistic Approach for the Correlations of Compression Index for Marine Clays", Journal of Geotechnical and Geo-Environmental Engineering, Volume 135, No. 12, December, 2009.

[14] Kumaz, T.F., and Ozkam, O., "Prediction of Compression Index Using Artificial Neural Network", Scientific Research and Essays, Volume 7, No. 31, 2012.

[15] Terzaghi, K., and Peck, R.B., "Soil Mechanics in Engineering Practice", John Villey and Sons, Inc., $3^{\text {rd }}$ Edition, 1967.

[16] Nishida, Y., "A Brief Note on Compression Index of Soil”, Journal of Soil Mechanics and Foundation Division, American Society for Civil Engineers, Volume 82, pp. 10271-102714, 1956.

[17] Renden-Herero, O., "Universal Compression Index Equation", Journal of Soil Mechanics and Foundation Division, American society for Civil Engineers, Volume 106, pp 1179-1200, 1980.

[18] Nagaraj, T.S., and Srinavasa, M.B.R., "Rationalization of Skemptons, Compressibility Equation", Geotechnique, Volume 33, No. 4, pp. 433-443, 1983.

[19] Nakase, A., Kamei, T., and Kusakabe, O., "Constitutive Parameters Estimated by Plasticity Index”, ASCE Journal of Geotechnical Engineering, Volume 114, No. 7, pp. $844-858,1988$. 